\title{
Lack of the Golgi phosphate transporter PHT4;6 causes strong developmental defects, constitutively activated disease resistance mechanisms and altered intracellular phosphate compartmentation in Arabidopsis
}

\author{
Sebastian Hassler ${ }^{1}$, Lilia Lemke ${ }^{1}$, Benjamin Jung ${ }^{1}$, Torsten Möhlmann ${ }^{1}$, Falco Krüger $^{2}$, Karin Schumacher ${ }^{2}$, Luca Espen ${ }^{3}$, \\ Enrico Martinoia ${ }^{4}$ and H. Ekkehard Neuhaus ${ }^{1, *}$ \\ ${ }^{1}$ Plant Physiology, University of Kaiserslautern, Erwin Schrödinger Straße, D-67653 Kaiserslautern, Germany, \\ ${ }^{2}$ Centre for Organismal Studies, Department of Plant Cell Biology, Ruprecht-Karls University, Heidelberg, Germany, \\ ${ }^{3}$ Dipartimento Produzione Vegetale, Università degli Studi di Milano, Milano, Italy, and \\ ${ }^{4}$ Plant Biology, University of Zürich, Zürich, Switzerland
}

Received 26 March 2012; revised 29 June 2012; accepted 10 July 2012

*For correspondence (e-mail neuhaus@rhrk.uni-kl.de).

\begin{abstract}
SUMMARY
The Golgi-located phosphate exporter PHT4;6 has been described as involved in salt tolerance but further analysis on the physiological impact of PHT4;6 remained elusive. Here we show that PHT4;6-GFP is targeted to the trans-Golgi compartment and that loss of function of this carrier protein has a dramatic impact on plant growth and development. Knockout mutants of pht4;6 exhibit a dwarf phenotype that is complemented by the homologous gene from rice (Oryza sativa). Interestingly, pht4; 6 mutants show altered characteristics of several Golgi-related functions, such as an altered abundance of certain N-glycosylated proteins, altered composition of cell-wall hemicelluose, and higher sensitivity to the Golgi $\alpha$-mannosidase and the retrograde transport inhibitors kifunensine and brefeldin A, respectively. Moreover, pht4;6 mutants exhibit a 'mimic disease' phenotype accompanied by constitutively activated pathogen defense mechanisms and increased resistance against the virulent Pseudomonas syringae strain DC3000. Surprisingly, pht4;6 mutants also exhibit phosphate starvation symptoms, as revealed at the morphological and molecular level, although total Pi levels in wildtype and pht4;6 plants are similar. This suggested that subcellular Pi compartmentation was impaired. By use of nuclear magnetic resonance (NMR), increased Pi concentration was detected in acidic compartments of pht4;6 mutants. We propose that impaired Pi efflux from the trans-Golgi lumen results in accumulation of inorganic phosphate in other internal compartments, leading to low cytoplasmic phosphate levels with detrimental effects on plant performance.
\end{abstract}

Keywords: inorganic phosphate, Golgi apparatus, vacuole, phosphate compartmentation, mimic disease, Arabidopsis.

\section{INTRODUCTION}

Phosphate-containing biomolecules are essential for all types of cells. Nucleic acids and ATP are among the most prominent such compounds, but other substances such as further nucleotides, many types of phosphorylated primary metabolites and various phospholipids are of similar importance. Phosphate in soils is not readily available, and Pi supplementation usually stimulates plant yield, plant development, and tolerance against biotic and abiotic stressors (Bucher, 2007). Given the importance of phosphate for many metabolic and molecular processes, it is not surprising that plants sense the cellular phosphate status (Ticconi et al., 2009) and adjust both gene expression and developmental processes accordingly (Müller et al., 2007; Nakamura et al., 2009).

Phosphate uptake into root cells is proton-coupled and catalyzed by plasma membrane-located PHT1-type carriers (Shin et al., 2004), representing one of several phosphate transporter sub-families. In addition to PHT1-type carriers (which have several isoforms), higher-plant genomes encode plastidic PHT2-type carriers, mitochondrial-located 
PHT3-type carriers and four isoforms of the structurally unrelated plastidic phosphate translocator ( $\mathrm{pPT}$ ) proteins that are located in the inner envelope membranes of plastids (Rausch and Bucher, 2002; Weber et al., 2005). In contrast to other PHT-type carriers, the latter group of phosphate carriers does not modify the phosphate concentration across the corresponding membrane, as pPT proteins catalyze a strictly coupled counter exchange of $\mathrm{Pi}$ and other phosphorylated intermediates (Fischer et al., 1997; Kammerer et al., 1998). The PHT4 sub-family of carriers comprises a total of six isoforms, five of which reside in the plastidic envelope (Guo et al., 2008a).

In addition to the transporters listed above, which have been characterized at the functional level, higher plants harbor several isoforms of membrane-located PHO proteins. PHO proteins clearly influence both cellular phosphate homeostasis and phosphate loading into the xylem, but their exact biochemical properties are still unresolved (Wang et al., 2004; Stefanovic et al., 2011).

PHT-type carriers in Arabidopsis form a large protein family (Roth et al., 2004), and show substantial amino acid sequence homology to the large solute carrier family 17 (SLC17) that is present in mammals and other eukaryotes. Most members of this transporter family reside in the plasma membrane, exhibit a wide substrate spectrum, and are typically sodium-driven in animals (Chang et al., 2004). Further SLC17 members in animals include the $\mathrm{H}^{+}$/ATP antiporter vesicular nucleotide transporter (VNUT) (Sawada et al., 2008) and various $\mathrm{H}^{+}$/organic anion antiporters that are able to transport, among others, glutamate, aspartate, sialin or sialic acid (Reimer and Edwards, 2004; Miyaji et al., 2008). These SLC17 members are located in endomembranes, namely Golgi-derived vesicles (Reimer and Edwards, 2004; Miyaji et al., 2008; Sawada et al., 2008).

Currently, our knowledge on phosphate transport across plant endomembranes such as the ER, Golgi or the vacuolar membrane is limited (Rausch and Bucher, 2002). The vacuole represents up to $90 \%$ of the cell volume and represents a dynamic intracellular Pi reservoir (Martinoia et al., 2007; Pratt et al., 2009). However, although the existence of dynamic $\mathrm{Pi}$ transport across the vacuolar membrane has been known for a long time (Martinoia et al., 2007), and despite the description of low- and high-affinity $\mathrm{Pi}$ uptake mechanisms, so far no distinct vacuolar $\mathrm{Pi}$ transporting protein has been identified at the molecular level (Rausch and Bucher, 2002; Martinoia et al., 2007).

Arabidopsis PHT4;6 has been identified as a Golgi-located phosphate transporter (Guo et al., 2008b) involved in $\mathrm{Pi}$ release from the Golgi compartment (Cubero et al., 2009). This mode of transport allows export of inorganic phosphate from the organellar lumen, and is required because ATPconsuming reactions or nucleotide sugar metabolism in this compartment continuously releases $\mathrm{Pi}$. The PHT4;6 gene is expressed ubiquitously in most plant organs, and does not show diurnal regulation as revealed for most of the five other Arabidopsis PHT4 genes (Guo et al., 2008a; Cubero et al., 2009).

Interestingly, PHT4;6 loss-of-function mutants show increased sensitivity against sodium stress as revealed by altered root morphology which is dependent on rising $\mathrm{NaCl}$ concentrations (Cubero et al., 2009). This observation is in line with a critical function of the Golgi apparatus in cell-wall synthesis and the observation that other cell-wall mutants also exhibit increased salt sensitivity (Koiwa et al., 2003; Shi et al., 2003; Frank et al., 2008; Kang et al., 2008).

Given the ubiquitous expression of the PHT4;6 gene (Guo et al., 2008a) and the critical function of the Golgi apparatus in an enormously wide array of cellular processes, we analyzed the physiological importance of PHT4;6 in more detail. In this study, we demonstrate that impaired PHT4;6 activity negatively affects whole plant development and provokes impaired function of several Golgi-associated processes. Moreover, we show that the corresponding loss-of-function mutant shows a 'mimic disease' phenotype at the morphological and molecular level. Surprisingly, pht4;6 mutants exhibit a Pi starvation response, and in vivo determination of subcellular Pi compartmentation in pht4;6 mutants indicated a so far unknown type of interaction between $\mathrm{Pi}$ efflux from the Golgi compartment and increased vacuolar Pi levels.

\section{RESULTS}

\section{PHT4;6 loss-of-function mutants show a dwarf phenotype and altered leaf characteristics}

To date, loss of a functional PHT4;6 gene has only been correlated with a single effect, namely altered root morphology under conditions of salt stress (Cubero et al., 2009). However, the experiments presented in that study were performed on plants grown on agar medium, and it was not analyzed whether absence of this carrier may affect the overall growth of Arabidopsis on soil.

To search for correlations between PHT4;6 activity and plant development, we grew wild-type and homozygous pht4;6 plants (Figure S1) on soil and analyzed their morphological appearance at various developmental stages. The chosen loss-of-function mutant pht4;6 was exactly the same as characterized previously (Cubero et al., 2009). We further confirmed the specificity of the effects in pht 46 plants by genetic construction of two independent complementation lines containing either the rice homolog OsPHT4;6 (Os11g08370) or the native Arabidopsis gene AtPHT4;6. Both complementations fully restored wild-type growth (Figures S2 and S3). After 8 weeks of growth, wildtype plants showed a fully developed rosette covering most of the pod surface (Figure 1a). In contrast, pht4;6 mutants exhibited markedly reduced growth (Figure $1 \mathrm{~b}$ ), which correlated with small curled leaves compared to wild-type 

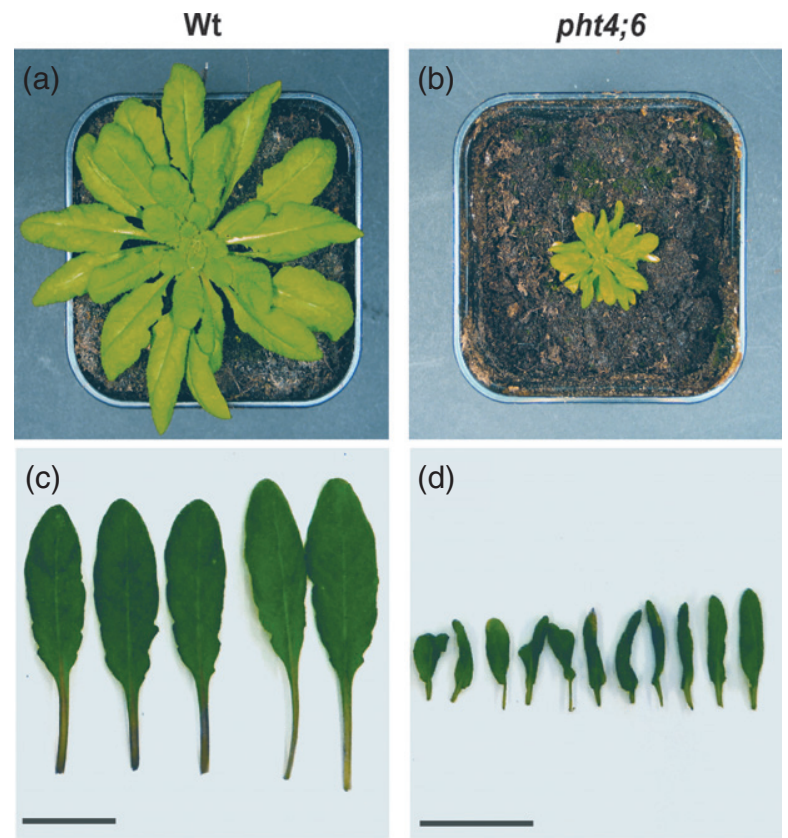

(d)

(e)

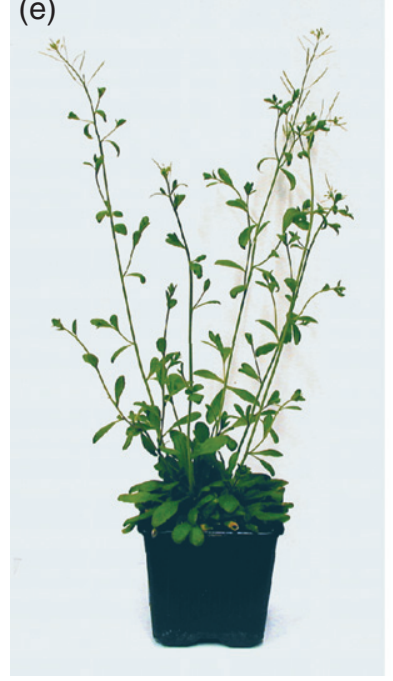

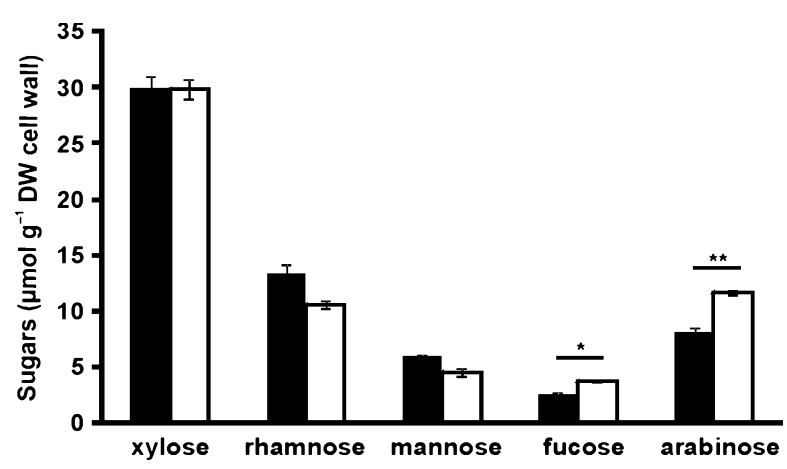

Figure 2. Cell-wall composition of wild-type and pht4;6 plants.

Cell walls were isolated from freeze-dried leaf material of 4-week-old wildtype (closed bars) and pht4;6 mutant (open bars) plants grown on soil. Error bars represent standard error $(n=3)$. Asterisks indicate a significant difference between wild-type and the transgenic line $\left({ }^{*} P<0.05 ;{ }^{*} P<0.005\right)$.

mutant plants (Figure 1f), further indicating impaired development.

\section{PHT4;6 is important for cell-wall sugar composition and influences Golgi-related processes}

PHT4;6 locates to the Golgi apparatus (Guo et al., 2008b; Cubero et al., 2009), but the exact location within this very complex cellular structure is unknown. Using co-expression of a PHT4;6-GFP construct with either cis-Golgilocated $\alpha$-mannosidase-RFP (Nebenführ et al., 2002) or trans-Golgi-located sialin transferase-DsRFP (ST-DsRFP) (Saint-Jore et al., 2002), we were able to clarify the subcellular location of PHT4;6 in more detail. A merged image of PHT4;6-GFP with $\alpha$-mannosidase-RFP at high magnification showed distinctly labeled sub-domains of the Golgi apparatus, whereas a merged image of PHT4;6-GFP with ST-DsRed revealed close overlap, indicating a trans-Golgi location of the PHT4;6 protein (Figure S2). Therefore, we assessed the effect of impaired PHT4;6 activity on several Golgi-located or Golgi-related processes such as hemicellulose synthesis, glycoprotein synthesis and vesicle transport.

To quantify hemicellulose composition, we grew wildtype plants and pht4;6 mutants for 4 weeks on soil, collected complete rosettes, and extracted and quantified hemicellulose-derived monosaccharides. Xylose, representing the most abundant sugar moiety, accumulates in wild-type and mutant lines to nearly identical levels, reaching approximately $30 \mu \mathrm{mol} \mathrm{gFW}^{-1}$ (fresh weight) (Figure 2). In contrast, the levels of rhamnose and mannose were slightly reduced in pht4;6 plants, and fucose and arabinose levels were significantly increased (Figure 2). These data demonstrate that impaired $\mathrm{PHT} 4 ; 6$ activity correlates with altered cell-wall compositions.

Some types of sugar moieties required for hemicellulose biosynthesis also serve in covalent modification of proteins this developmental stage, no siliques were established on 


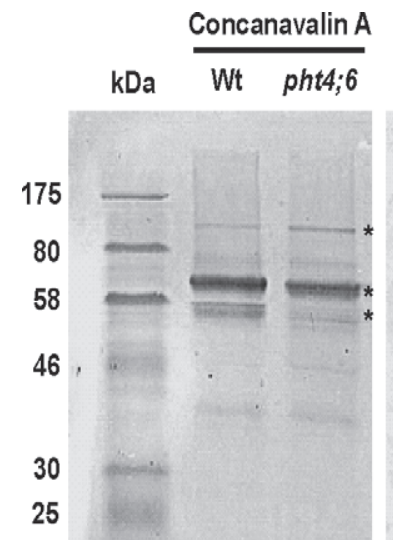

(a)

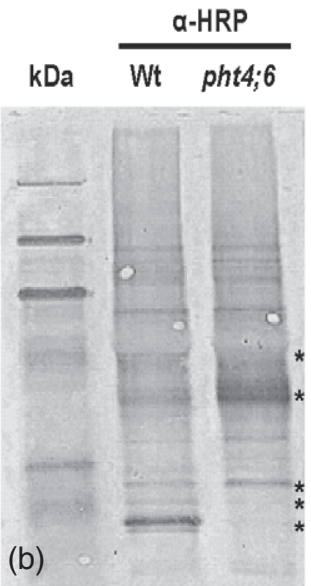

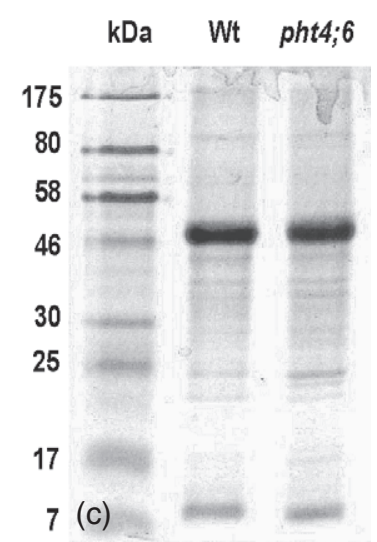

Figure 3. Glycosylation patterns of proteins extracted from wild-type $(\mathrm{Wt})$ or pht4;6 plants. (a) Immunoblot analysis of total protein extracted from 4-week old wild-type or pht4;6 leaves. Protein $(15 \mu \mathrm{g})$ was subjected to SDSPAGE. The clot was analyzed using the lectin concanavalin A.

(b) Immunoblot performed using $\alpha$-horseradish peroxidase antibody. Asterisks in (a) and (b) indicate altered protein abundance.

(c) Total protein of wild-type and pht4;6 leaves separated via SDS-PAGE as a protein loading control. in the ER and Golgi compartments. Therefore, we also searched for putative modifications in the protein glycosylation pattern. Using concanavalin A, a lectin that is able to bind high-mannose-type $\mathrm{N}$-glycans attached to polypeptides (Mandal and Brewer, 1993), we demonstrated that at least three proteins of unknown nature show altered abundance in pht4;6 leaves compared to wild-type plants (Figure 3a). Similarly, use of $\alpha$-horseradish peroxidase antibody, which is able to bind complex-type $\mathrm{N}$-glycans (especially fucose and xylose residues, Wilson et al., 1998), revealed that at least five proteins in pht $4 ; 6$ leaves show altered abundance (either increased or decreased, respectively) when compared to wild-type (Figure 3b).

The Golgi apparatus and the ER communicate via permanent anterograde and retrograde flux of vesicles. Thus, it may be hypothesized that altered Golgi properties may also impair ER-resident processes. Inhibition of essential reactions located in the ER induces luminal accumulation of incorrectly folded, newly synthesized proteins. This process leads to the so-called 'unfolded protein response' characterized by increased expression of marker genes encoding
ER-associated chaperones (Lai et al., 2007). Interestingly, using the genes coding for the ER-located proteins Bip1/2, Bip3, calreticulin1/2 (CRT1/2), calnexin1 (CNX1), Shepherd and the transcription factor BZIP60 as molecules involved in plant protein quality control (Liu and Howell, 2010), we found that all of these genes exhibit markedly increased expression levels in pht4;6 plants compared to wild-type plants (Figure 4a,b). Obviously, pht4;6 mutants show a unfolded protein response in their leaf tissue (Figure $4 a, b$ ).

Kifunensine is a potent inhibitor of Golgi- and ER-resident $\alpha$-mannosidases, and thus affects protein glycosylation (Hering et al., 2005). To verify whether protein glycosylation processes are more sensitive in mutants than in wild-type plants, we grew all lines under increasing kifunensine concentrations and checked for altered phenotypic appearances (Figure 5a). At a concentration of up to $30 \mu \mathrm{m}$, kifunensine did not affect the root morphology or length in wild-type plants (Figure 5a). In contrast, even $5 \mu \mathrm{m}$ kifunensine strongly inhibited growth of pht $4 ; 6$ roots. At this concentration, root length was only half that observed in the absence of kifunensine. Moreover, the root tips showed
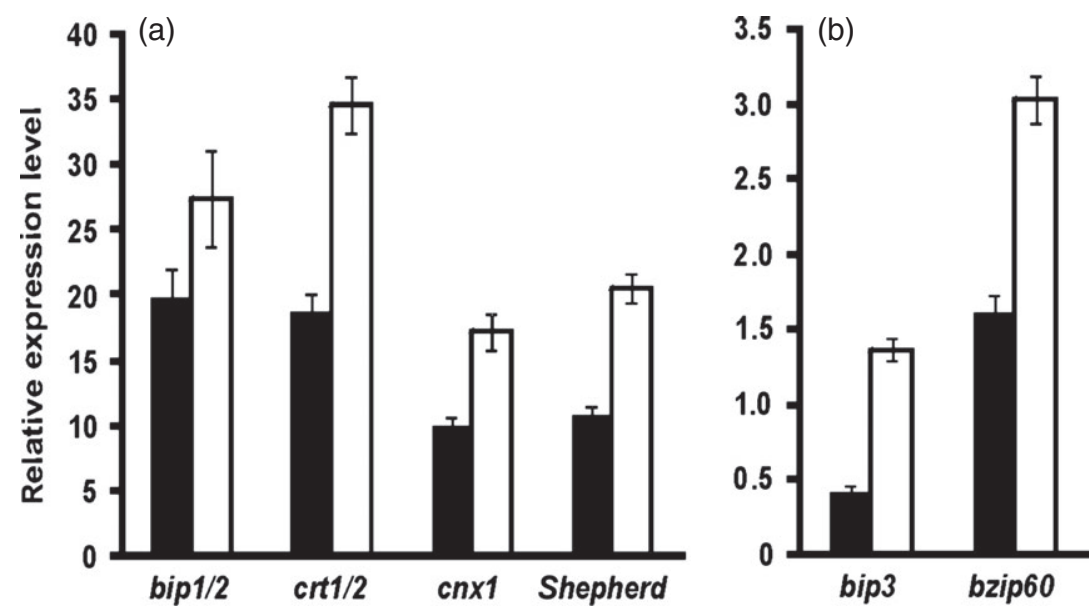

Figure 4. Real-time PCR analysis of expression levels of genes involved in Arabidopsis protein quality control.

(a) mRNA levels of bip 1/2, crt1/2, cnx 1 and shepherd in wild-type (closed bars) and pht4;6 (open bars) plants.

(b) mRNA levels of bip3 and bzip60 in wild-type (closed bars) and pht4;6 (open bars) plants. Leaves of 4-week-old plants grown on soil were used for extraction of total RNA. Error bars indicate standard error $(n=3)$. 
Figure 5. Effect of inhibitors on wild-type and pht $4 ; 6$ growth pattern.

(a) Wild-type (Wt) and pht4;6 plants were grown for 15 days on half-strength MS agar plates supplemented with $0,5,15$ or $30 \mu \mathrm{m}$ kifunensine (Kif), which is a potent inhibitor of class I $\alpha$ mannosidases.

(b) Wild-type (Wt) and pht4;6 lines were cultivated for 3 weeks on half-strength MS agar plates without addition of inhibitors.

(c) Effects of $10 \mu \mathrm{m}$ brefeldin A on wild-type (Wt) and pht $4 ; 6$ plants 3 weeks post-germination. (d) Effects of $15 \mu \mathrm{m}$ brefeldin A on wild-type (Wt) and pht4;6 plants 3 weeks post-germination.
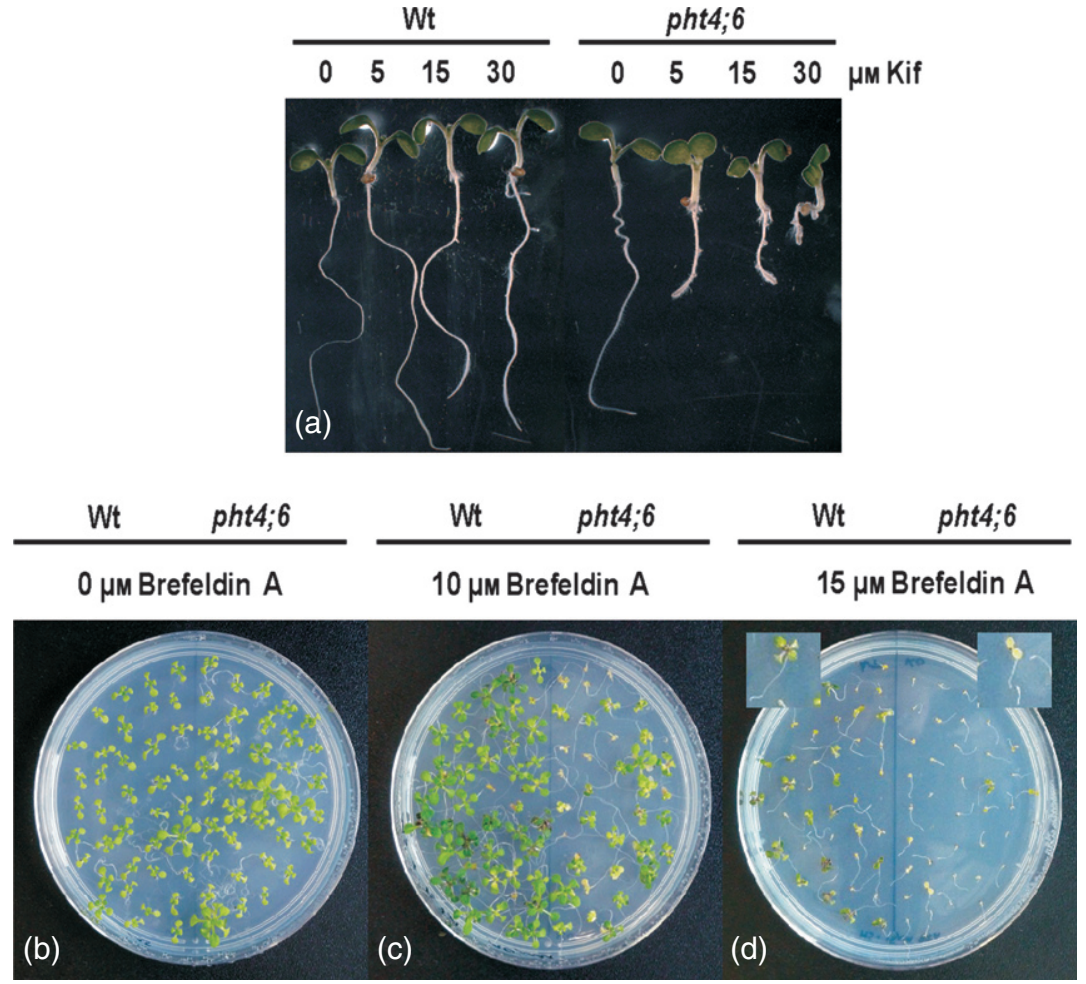

a swollen and bushy phenotype (Figure 5a). At a concentration of $30 \mu \mathrm{m}$ kifunensine, roots of pht $4 ; 6$ plants appeared hardly developed (Figure 5a).

Brefeldin A inhibits Golgi vesicle transport in plant cells (Nebenführ et al., 2002). Thus, we analyzed whether brefeldin A acts differently on wild-type and pht4;6 cells. To do this, we grew wild-type and mutant plants for 3 weeks on agar plates in the presence of either 10 or $15 \mu \mathrm{m}$ brefeldin $A$. Without brefeldin A, wild-type and pht4;6 plants grew similarly (Figure $5 \mathrm{~b}$ ), but growth of pht4;6 was inhibited in the presence of $10 \mu \mathrm{m}$ brefeldin $\mathrm{A}$ but that of wild-type plants was not (Figure $5 \mathrm{c}$ ). At $15 \mu \mathrm{m}$ brefeldin A, growth of mutant and wild-type plants was reduced, but pht4;6 mutants were much more affected, as indicated by strongly impaired development accompanied by chlorotic leaves (Figure 5c,d).

\section{pht4;6 mutants show altered pathogen defense-related mechanisms}

It is known that controlled vesicle flux is critical for various pathogen defense mechanisms of plant cells (Collins et al., 2003; Kwon et al., 2008). As we had obtained evidence for modified Golgi properties and impaired post-Golgi vesicle flux (Figures 2, 3 and $5 c, d$ ), we also searched for putatively altered defense reactions in pht4;6 mutants.

Salicylic acid (SA) is central to plant pathogen response mechanisms, and accumulates rapidly in tissues subsequent to infections (Thulke and Conrath, 1998). Moreover, after synthesis, SA itself serves as an endogenous signal that stimulates expression of various pathogen-related $(P R)$ genes (Shah, 2003). Thus, we first quantified SA levels in wild-type and pht4;6 leaves, and showed that wild-type plants accumulate free SA to a level of $0.59 \mathrm{nmol} \mathrm{gFW}^{-1}$ whereas pht4;6 leaves contained more than twice as much $\mathrm{SA}$, i.e. $1.4 \mathrm{nmol}$ free SA per $\mathrm{gFW}$ (Figure 6a). In plants, SA may exist in either a free form or in conjugation with other molecules (Thulke and Conrath, 1998). Interestingly, the difference between conjugated SA in wild-type and mutant tissues was even greater than observed for the free SA form. Wild-type plants accumulated approximately $7.5 \mathrm{nmol}$ conjugated SA per gFW, whereas pht $4 ; 6$ plants contained over seven times more conjugated SA, i.e. $58 \mathrm{nmol} \mathrm{SA}$ per $\mathrm{gFW}$ (Figure 6b).

As mentioned above, SA serves as an endogenous inducer of several $P R$ genes. Using $P R 1$ (an SA-induced gene of unclear function), PR2 (ß-1,3-glucanase), GSTF6 (a glutathione transferase) and $P A L$ (encoding phenylalanine ammonia- lyase) as pathogen-related reporter genes, we demonstrated that all of these genes exhibit increased expression in pht4;6 plants compared to corresponding wild-type plants (Figure 6c).

To obtain further information regarding the involvement of PHT4;6 activity in defense mechanisms, we assessed stimulation of PHT4;6 expression by pathogens. To do this, wild-type leaves were inoculated with either a virulent or a non-virulent Pseudomonas syringae strain, i.e. DC3000 or 


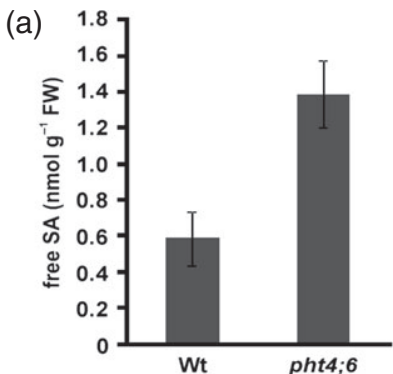

(b)

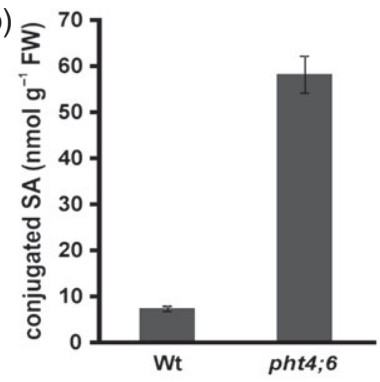

(c)

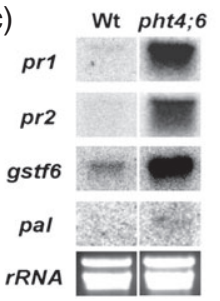

(d)

Oh $4 \mathrm{~h} \quad 8 \mathrm{~h} \quad 24 \mathrm{~h}$ Oh $4 \mathrm{~h} \quad 8 \mathrm{~h} \quad 24 \mathrm{~h}$ oh $4 \mathrm{~h} \quad 8 \mathrm{~h} \quad 24 \mathrm{~h}$
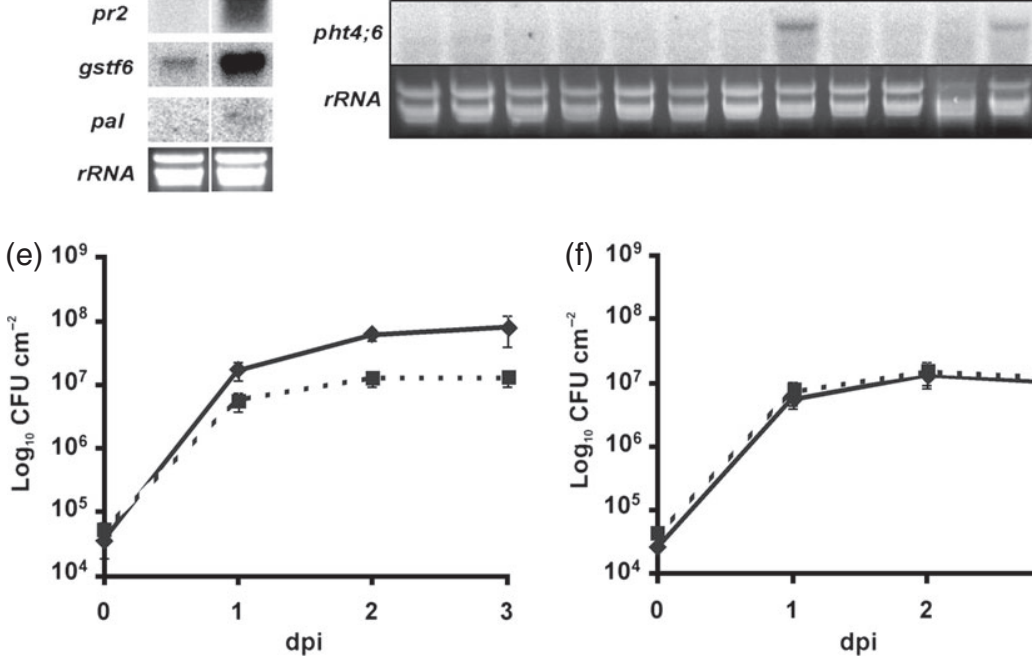

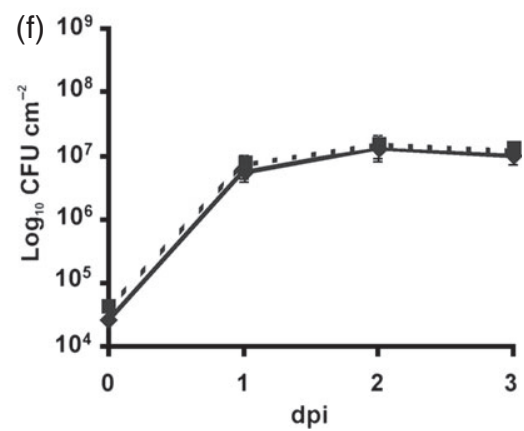

Figure 6. Lack of pht4;6 leads to an increased pathogen response.

$(a, b)$ Quantification of free (a) and conjugated salicylic acid (SA) (b) in rosette leaves of 4-weekold wild-type (Wt) and pht4;6 plants. Error bars indicate standard error $(n=3)$.

(c) Northern blot analysis showing the expression of pr1, pr2, gstf6 and pal genes in wild-type (Wt) and pht4;6 plants. Ethidium bromidestained rRNA was used as a loading control.

(d) Expression pattern of pht4;6 in 4-week-old wild-type leaves after infection with the Pseudo monas syringae strains Dc3000 or DC3000 AvrRpt2. $\mathrm{MgCl}_{2}$ solution was used as a control. For Northern blot analysis, plants were harvested after $0,4,8$ and $24 \mathrm{~h}$ post-infection. Ethidium bromide-stained rRNA was used as a loading control.

(e) $P$. syringae DC3000 population in 4-week-old wild-type (diamond) and pht4;6 (square) plants. (f) P. syringae DC3000 AvrRpt2 population in 4-week-old wild-type (diamond) and pht4;6 (square) plants. Plants were infiltrated with $5 \times 10^{5} \mathrm{cfu} \mathrm{ml}^{-1}$ of Pst DC3000 or Pst DC3000 AvrRpt2, and harvested 0, 1, 2 and 3 days postinoculation (dpi).
DC3000 AvrRpt2, respectively. The PHT4;6 gene, which hardly responds to other types of biotic or abiotic stress stimuli (Zimmermann et al., 2004), was markedly induced after $24 \mathrm{~h}$ of infection with the virulent strain DC3000, whereas the avirulent $P$. syringae strain DC3000 AvrRpt2 provoked only weak accumulation of PHT4;6 mRNA (Figure $6 \mathrm{~d}$ ).

To obtain evidence for altered pathogen resistance of pht4;6 plants, we inoculated leaves from wild-type and mutants with either $P$. syringae strain DC3000 or DC3000 AvrRpt2, respectively. After 1, 2 or 3 days of incubation, bacteria were re-isolated from leaves and their titers quantified (Figure $6 \mathrm{e}, \mathrm{f}$ ), and it was found that pht4;6 plants show markedly increased resistance against infection by the virulent P. syringae strain DC3000 (Figure 6e), whereas colonization of wild-type and pht4;6 leaves by the avirulent strain DC3000 AvrRpt2 occurred with a similar efficiency (Figure 6f).

Plants have the ability to immobilize and inactivate pathogens by inducing cell death of infected leaf areas. As the pathogen defense mechanisms described above differ between wild-type and pht4;6 plants, we further assessed differences between these plant lines. Trypan blue labels dead plant cells, and the abundance of blue areas on pht $4 ; 6$ leaves was significantly higher than on corresponding wildtype leaves (Figure 7a,b). Hydrogen peroxide is synthesized by infected plant tissues to inhibit pathogen development. Using 3,3'-diaminobenzidine (DAB) staining, we found that pht4;6 leaves accumulate significantly higher $\mathrm{H}_{2} \mathrm{O}_{2}$ levels than wild-type leaves (Figure 7c,d). Similarly, callose, representing a polysaccharide, responsible for sealing of leafsurface injuries and known to accompany early defense reactions characterized by apoplastic $\mathrm{H}_{2} \mathrm{O}_{2}$ bursts, is much more abundant in mutant than in wild-type leaves (Figure $7 e, f)$.

\section{PHT4;6 activity is critical for homeostasis of inorganic phosphate}

Although two research groups demonstrated that PHT4;6 acts as a phosphate-transporting carrier protein that is likely to export phosphate from the Golgi to the cytosol (Guo et al., 2008b; Cubero et al., 2009), neither phosphate homeostasis nor phosphate metabolism have yet been analyzed in corresponding loss-of-function mutants.

To assess the effect of Pi on pht4;6 mutants, we grew wildtype and mutant plants on soil under either standard conditions or conditions of increased Pi supply $(25 \mathrm{~mm}$ Figure $8 a-d)$. pht $4 ; 6$ plants show a dwarf phenotype under 

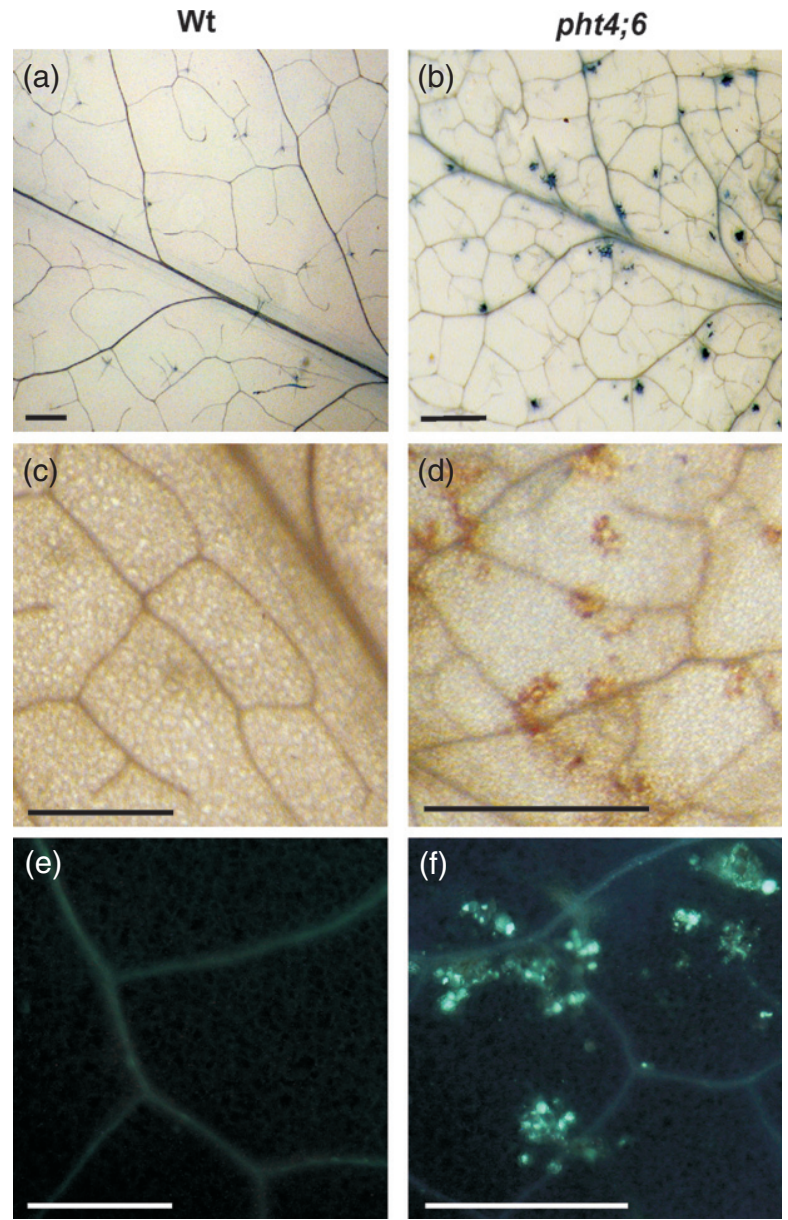

Figure 7. Occurrence of leaf lesions on wild-type (Wt) and pht4;6 plants (a, b) Leaf tissue of wild-type (a) and pht4;6 (b) plants stained with trypan blue. Scale bar $=0.5 \mathrm{~mm}$.

(c, d) Histochemical detection of $\mathrm{H}_{2} \mathrm{O}_{2}$ in wild-type (c) and pht4;6 (d) plants. Scale bar $=1 \mathrm{~mm}$.

$(\mathrm{e}, \mathrm{f})$ Detection of callose fluorescence in wild-type (e) and pht4;6 (f) leaves. Scale bar $=0.5 \mathrm{~mm}$. Plants were grown for 4 weeks on soil.

standard growth conditions compared to wild-type plants (Figures $1 \mathrm{a}, \mathrm{b}$ and $8 \mathrm{a}, \mathrm{b})$. Interestingly, addition of $\mathrm{Pi}(25 \mathrm{~mm}$ ) to the supplied water did not alter the growth of wild-type plants significantly, but clearly stimulated growth of pht4;6 plants (Figure 8c,d).

With this effect in mind, we quantified the total phosphate content in both plant lines grown under either standard or high-Pi conditions. Under standard growth conditions, Pi levels in wild-type and pht4;6 plants were similar: $4.86 \pm$ $0.5 \mu \mathrm{mol} \mathrm{gFW}{ }^{-1}$ in wild-type and $4.1 \pm 0.52 \mu \mathrm{mol} \mathrm{gFW}^{-1}$ in mutant plants (Figure 9). Because both phosphate and sulfate accumulate in the vacuole (Martinoia et al., 2007), and as both types of molecules represent divalent anions, it was interesting to observe that pht4;6 plants had significantly higher $\mathrm{SO}_{4}{ }^{2-}$ levels than wild-type plants, namely $22.33 \pm 0.84 \mu \mathrm{mol} \mathrm{gFW}^{-1}$ in mutants compared to 11.48
Wt
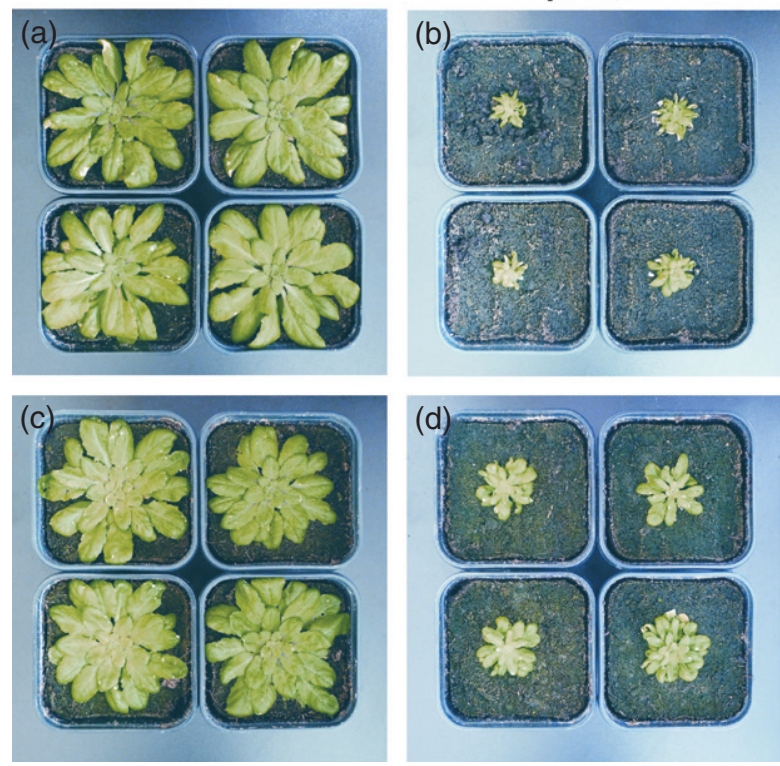

Figure 8. Effect of phosphate supplement on wild-type (Wt) or pht4;6 growth $(\mathrm{a}, \mathrm{b})$ Wild-type and pht4;6 plants were grown for 7 weeks on soil without $\mathrm{KH}_{2} \mathrm{PO}_{4}$

(c, d) Seven-week old wild-type and pht4;6 plants that were watered using water supplemented with $25 \mathrm{~mm} \mathrm{KH}_{2} \mathrm{PO}_{4}$

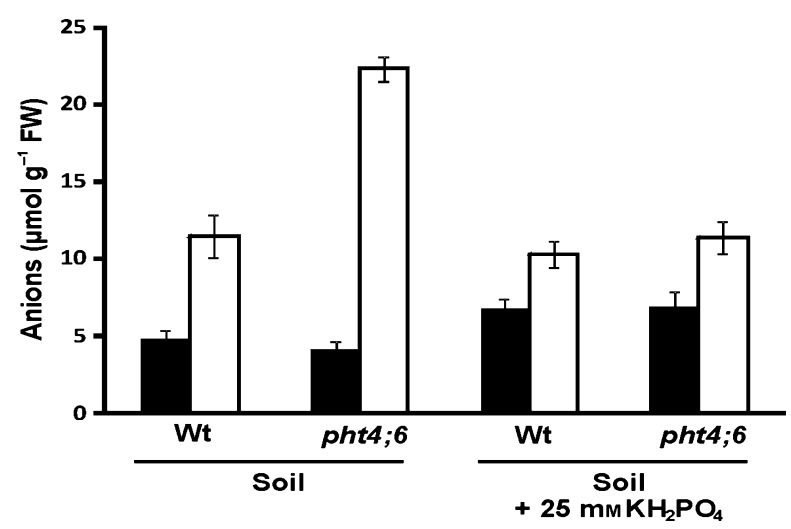

Figure 9. Quantification of phosphate and sulfate in wild-type (Wt) and pht4;6 mutant plants.

Phosphate (closed bars) and sulfate (open bars) content was determined in leaves of 7-week-old wild-type and pht4;6 plants. Plants were grown on soil with or without addition of phosphate $(25 \mathrm{~mm})$. Error bars represent standard error $(n=4)$.

$\pm 1.4 \mu \mathrm{mol} \mathrm{gFW}^{-1}$ in wild-type leaves (Figure 9). Remarkably, addition of $\mathrm{Pi}$ into the supplied water resulted in a slight increase in inorganic phosphate in both genotypes, reaching approximately $7.0 \mu \mathrm{mol} \mathrm{gFW}^{-1}$ (Figure 8). However, under these conditions (which stimulated growth of pht4;6 plants, Figure $8 a-d)$, the sulfate levels in mutants were very similar to those in wild-type plants (approximately $11.0 \mu \mathrm{mol}$ $\mathrm{gFW}^{-1}$, Figure 9). 


\section{PHT4;6 activity is critical for inorganic phosphate compartmentation}

The observation that addition of $\mathrm{Pi}$ to the water promotes growth of pht4;6 plants (Figure $8 \mathrm{a}-\mathrm{d}$ ) is an indirect indication of a Pi starvation syndrome. To obtain molecular evidence for a putative $\mathrm{Pi}$ starvation phenotype at the cellular level, we quantified the expression of genes known to respond to low Pi levels (Müller et al., 2007). The selected genes encode the transcription factors WRKY38 and WRKY75, the $3^{\prime}\left(2^{\prime}\right), 5^{\prime}$-bisphosphate nucleotidase SAL2 (At5g64000), and the plasma membrane-located phosphate importer PHT1;4 (Müller et al., 2007). In leaves of pht4;6 mutants, all four Pi-responsive genes were drastically (4.5-19-fold) up-regulated compared to wild-type plants (Figure 10). The plant vacuole represents the largest storage organelle for inorganic phosphate (Martinoia et al., 2007). Thus, it was tempting to analyze differences in vacuolar $\mathrm{Pi}$ levels in wild-type and pht4;6 plants. To do this, all plant lines were grown on soil and vacuolar Pi levels were quantified by NMR. NMR is a suitable method to quantify Pi levels at the subcellular level under in vivo conditions, i.e. on intact plant material (Espen et al., 2000; Pratt et al., 2009; Stefanovic et al., 2011).

Both wild-type and pht4;6 plants accumulated large amounts of $\mathrm{Pi}$ in the vacuole (Figure 11). After quantification of the NMR signals, we determined that mutant plants contained substantially increased phosphate levels in the
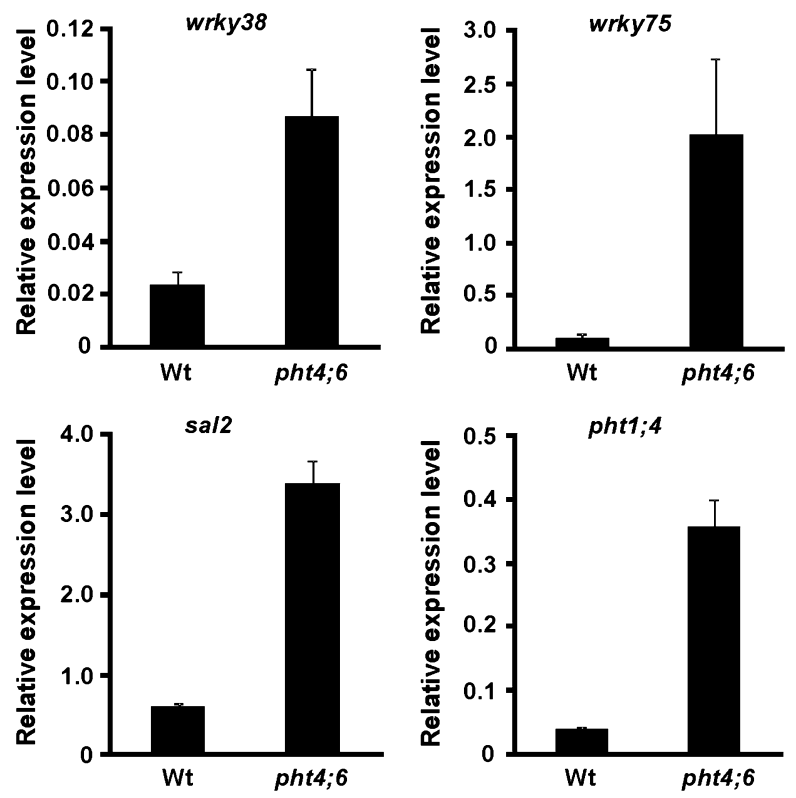

Figure 10. Relative expression of genes induced upon phosphate starvation quantified using quantitative RT-PCR.

mRNA levels of transcription factors wrky38 and wrky75, the $3^{\prime},\left(2^{\prime}\right), 5^{\prime}-$ bisphosphate nucleotidase sal2 and the plasmamembrane phosphate transporter pht 1;4 in wild-type (Wt) and pht4;6 plants. Leaves of 4-week-old plants grown on soil were used for extraction of total RNA. Error bars indicate standard error $(n=3)$.

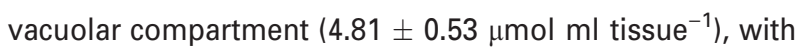
$40 \%$ more vacuolar $\mathrm{Pi}$ than present in corresponding wildtype vacuoles $\left(3.40 \pm 0.21 \mu \mathrm{mol} \mathrm{ml} \mathrm{tissue}{ }^{-1}\right)$. Our NMR studies did not allow exact determination of cytoplasmic $\mathrm{Pi}$ levels (Figure 11), which may lead to under-estimation of the cytoplasmic $\mathrm{Pi}$ in wild-type plants. This is in agreement with the generally very low cytosolic Pi levels in Arabidopsis and other plant species (Pratt et al., 2009), representing only a few per cent of total cellular inorganic phosphate (Espen et al., 2000). However, the NMR signal pattern observed in our experiments concurs with recent Pi NMR data obtained on Arabidopsis leaves (Stefanovic et al., 2011).

\section{DISCUSSION}

The Golgi apparatus acts as the cellular site for many reactions involved in cell-wall and protein modifications, as well as being a structure required for transport of proteins that enter the secretory pathway. The complement of transport proteins in membranes of the Golgi apparatus is still widely unknown, although a few proteins responsible for nucleotide sugar, monosaccharide or manganese transport have been identified in this plant cell compartment (Handford et al., 2004; Wang et al., 2006; Peiter et al., 2007). In addition to the proteins mentioned above, PHT4;6 was identified as

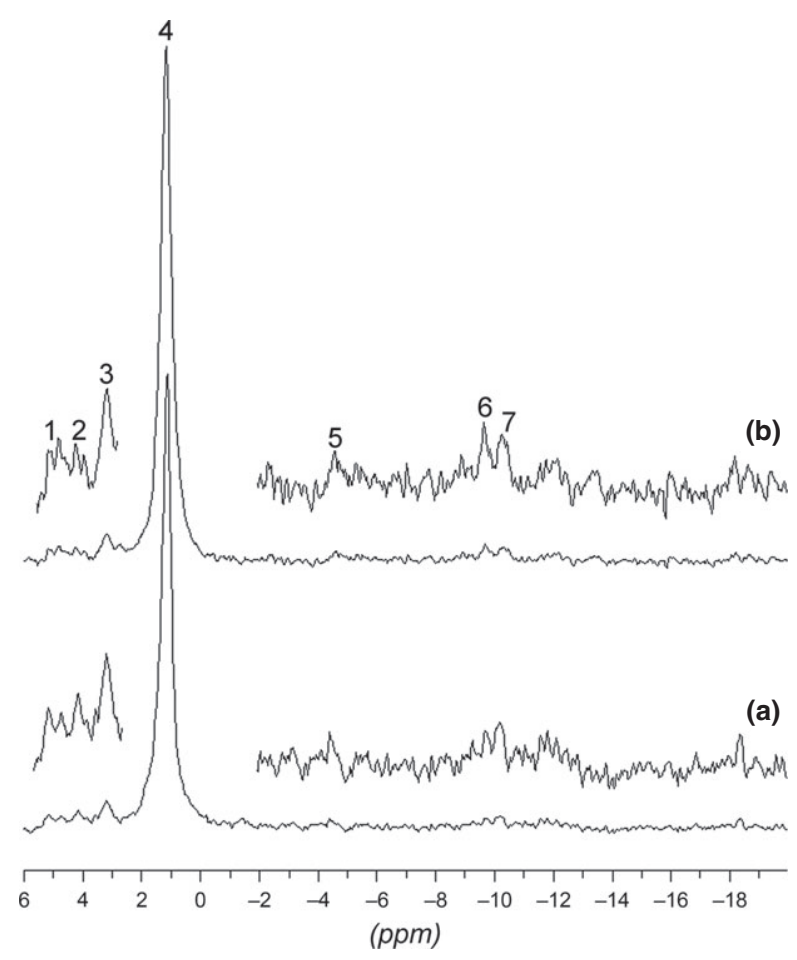

Figure 11. ${ }^{31} \mathrm{P}-\mathrm{NMR}$ spectra of wild-type (a) and pht4;6 (b) leaves.

The spectra were acquired with a $6 \mathrm{sec}$ recycle time and are the sum of 2000 scans. The resonance assignments are as follows: peak 1, Glc6P and other phosphomonoesters; peak 2, phosphocholine; peak 3, cytoplasmic phosphate; peak 4, vacuolar phosphate; peak 5, $\gamma$-phosphate of NTP and $\beta$-phosphate of NDP; peak $6, \alpha$-phosphates of NTP and NDP; peak 7, UDP$\mathrm{Glc}$ and $\mathrm{NAD}(\mathrm{P})(\mathrm{H})$. Some regions are shown on an expanded scale $(4 \times)$. 
the first phosphate carrier located in this cellular domain (Guo et al., 2008b). The Golgi lumen contains various enzymatic reactions that continuously release inorganic phosphate during hemicellulose synthesis, or during protein and lipid glycosylation. These latter types of reaction produce nucleoside diphosphates in the lumen that must be dephosphorylated prior to export into the cytosol (Hirschberg, 1997; Handford et al., 2004). The resulting inorganic phosphate moiety represents the PHT4;6 substrate (Cubero et al., 2009) as this carrier was characterized as a Pi facilitator working independently of the proton or sodium gradient (Guo et al., 2008b).

So far, increased sensitivity against salt stress accompanied by swollen root tips was the sole phenotypic alteration described for the pht4;6 mutant (Cubero et al., 2009). However, absence of PHT4;6 inhibits development of the whole plant (Figure 1a-e), not only the root tissue, when under salt stress (Cubero et al., 2009). Up to now, the PHT4;6 protein abundance in various organs or cells has not been quantified directly, but the strong effect of PHT4;6 activity on whole plant development (Figure 1a-e) is in line with the general importance of Golgi-related processes for cell function and the ubiquitous expression of the corresponding gene in most types of Arabidopsis tissue (Guo et al., 2008a). The more detailed analysis has revealed that the protein glycosylation pattern, hemicellulose composition, vesicle flux and ER-related processes are affected in cells lacking $\mathrm{PHT} 4 ; 6$ activity (Figures 2-5).

Against the background of such a substantial alteration of Golgi-resident processes, a direct correlation of increased salt sensitivity with altered cell-wall properties as proposed previously (Cubero et al., 2009) may not exist, although several mutants with altered cell-wall properties or modified protein glycosylation patterns do show increased salt sensitivity (Koiwa et al., 2003; Shi et al., 2003; Frank et al., 2008). In fact, the strong effect of kifunensine on pht4;6 plants resembles the increased salt sensitivity observed for Arabidopsis mutants lacking mannosidase I and II (Kang et al., 2008), and thus supports a genetic interaction of latter enzmyes with pht4;6 in the Golgi. However, in recent reports, endomembrane-located transport processes and regulatory mechanisms therein have received more and more attention with respect to plant sodium chloride tolerance. For example, it was shown that impaired activity of the Golgi-located V-ATPase in Arabidopsis provoked decreased tolerance against salt (Krebs et al., 2010). Also, mutants lacking the vesicle-associated sodium/proton antiporters NHX5 and NHX6 showed increased sodium sensitivity (Bassil et al., 2011), whereas over-expression of the vesicle trafficking regulation gene RabG3e increased salt tolerance (Mazel et al., 2004). These independent observations clearly indicate involvement of Golgi-derived vesicles in sodium tolerance. In addition, a causality between the increased salt sensitivity of pht $4 ; 6$ plants and altered cell- wall properties (Cubero et al., 2009) becomes even more questionable as pht4;6 mutants also exhibit a markedly stimulated unfolded protein response (Figure 4). However, to activate salt stress genes, ER-located processes must obviously be undisturbed, because a constitutively activated unfolded protein response, as present in pht 46 plants (Figure 4), negatively influences abiotic stress responses in plants (Liu and Howell, 2010).

It is remarkable that pht4;6 mutants show altered Golgi vesicle flux properties (as directly indicated by increased sensitivity to brefeldin A, Figure $5 b-d$ ) and substantially increased levels of SA (Figure 6a,b). Interestingly, other mutants inhibited in post-Golgi vesicle transport are also characterized by constitutively increased SA levels. Recently, an Arabidopsis mutant lacking two Qa-SNARE (soluble $\mathrm{N}$-ethylmaleimide-sensitive factor attachment receptor) proteins residing in the trans-Golgi network showed impaired vesicle flux from the trans-Golgi to the trans-Golgi network, and, similar to pht4;6 plants, constitutively increased SA levels (Uemura et al., 2012). Thus, it appears justified to assume that altered post-Golgi vesicle fluxes directly affect SA metabolism in Arabidopsis.

The observation that the PHT4;6 gene is induced by virulent DC3000 P. syringae cells (Figure 6d) is in line with stimulation of the secretory machinery during pathogen infection. Similar to PHT4;6, the gene encoding the Arabidopsis t-SNARE homolog SNAP33 is strongly activated upon Pseudomonas infection (Wick et al., 2003). Such stimulation of genes involved in vesicle flux upon pathogen challenge is consistent with stimulated expression of several other genes encoding ER-located proteins and the increased vesicle flux required to release hydrolytic enzymes into the apoplast as an early plant defense response (Uknes et al., 1992; Denecke et al., 1995).

We observed that, in contrast to wild-type, leaves from pht4;6 plants show spontaneous necrotic lesions, increased $\mathrm{H}_{2} \mathrm{O}_{2}$ levels, increased expression of a wide set of $P R$ genes, and stimulated callose deposition (Figures 6 and 7). The accumulation of callose may be interpreted as a response to the elevated $\mathrm{H}_{2} \mathrm{O}_{2}$ levels in pht4;6 leaves, as this reactive oxygen species probably triggers the hypersensitive response in terms of programmed cell death, resulting in necrotic lesions. Thus, pht4;6 plants are 'mimic disease' mutants, showing morphological, physiological and molecular symptoms of infection without direct contact with pathogens. Examples of such 'mimic disease' mutants are the loss-of-function mutants cad1 (lacking a membrane attack complex perforin protein) and mapk4 (lacking a MAP kinase), which also show spontaneous leaf lesions and spontaneous activation of the molecular defense machinery (Petersen et al., 2000; Morita-Yamamuro et al., 2005), closely resembling the pht4;6 phenotype.

PHT4;6 belongs to the large PHT family of putative phosphate carriers in Arabidopsis. Moreover, recombinant 
synthesis of PHT4;6 and subsequent transport experiments provided clear evidence for the Pi transport competence of this membrane protein (Guo et al., 2008b; Cubero et al., 2009). Given this, and bearing in mind that the pht $4 ; 6$ loss-offunction mutant shows a strong dwarf phenotype and massively altered Golgi properties (Figures 1-5), it was surprising to observe that the total Pi content was almost identical in wild-type and mutant plants (Figure 9). Nevertheless, adding $\mathrm{Pi}$ to the daily supplied water stimulates growth of the pht4;6 mutant but not the wild-type (Figure 8). This observation provided the first evidence for an intracellular phosphate starvation phenotype, which is substantiated by various further observations. First, independent genes responsive to low $\mathrm{Pi}$ are markedly up-regulated in pht4;6 mutants (Figure 10). Obviously, internal Pi release mechanisms such as increased expression of the gene SAL2 (Figure 10), encoding the enzyme $3^{\prime}\left(2^{\prime}\right), 5^{\prime}$-bisphosphate nucleotidase, are activated in pht $4 ; 6$ mutants. This enzyme releases $\mathrm{Pi}$ from 3'Phosphoadenosine-5'-phospho sulfate (PAPS), which is required for sulfate assimilation in higher plants. Thus, accumulation of free sulfate is obvious in pht4;6 plants under limiting phosphate conditions, but not under conditions of high phosphate supply (Figure 9), which also partially ameliorated the dwarf phenotype (Figure 8). Second, pht4;6 plants show a markedly increased vacuolar level of Pi (Figure 11), although the total Pi content in mutant and wild-type plants is nearly identical (Figure 9).

Although cytosolic Pi concentrations could not be determined directly, the total $\mathrm{Pi}$ concentrations are similar in wildtype and pht4;6 plants, thus the observation that mutant plants contain $40 \%$ more vacuolar $\mathrm{Pi}$ suggests that the cytoplasm of pht4;6 plants is strongly depleted in Pi. As the lumen of the Golgi is also acidic (Maeda and Kinoshita, 2010), our results do not allow us to distinguish between vacuolar and Golgi Pi levels. In fact, the increased sensitivity of pht4;6 mutants to brefeldin A may be caused by a block of post-Golgi traffic, leading to an even stronger impaired $\mathrm{Pi}$ escape from the Golgi to the vacuole, when compared to wild-type plants (Figure $5 b-d$ ). Obviously, neither other $\mathrm{Pi}$ transporters nor PHO-type carriers are able to compensate for the loss of a functional PHT4;6 protein. Our data independently support the recent view that Pi metabolism and transport in the Golgi and trans-Golgi network play an important role in intracellular phosphate homeostasis in Arabidopsis (Arpat et al., 2012).

\section{EXPERIMENTAL PROCEDURES}

\section{Plant material and growth conditions}

Arabidopsis thaliana ecotype $\mathrm{Col}-0$ and transgenic plants were grown on standard soil (ED-73, Patzer GmbH, www.einheitserde.de) in a growth chamber under a $10 \mathrm{~h}$ light/14 $\mathrm{h}$ dark regimen at $22^{\circ} \mathrm{C}$ and $125 \mu \mathrm{mol}$ quanta $\mathrm{m}^{-2} \mathrm{sec}^{-1}$. The pht4;6 T-DNA insertion mutant SAIL\#1404_809_B01 was obtained from the Nottingham Arabidopsis Stock Centre (http://arabidopsis.info). For phosphate supplementation assays, plants were watered regularly with water supplemented with $25 \mathrm{~mm} \mathrm{KH}_{2} \mathrm{PO}_{4}$.

Prior to germination, seeds were surface-sterilized and incubated for 2 days in the dark for imbibition. For growth experiments with kifunensine (Sigma, http://www.sigmaaldrich.com) and brefeldin A (Sigma), surface-sterilized seeds were sown on Murashige and Skoog (MS) plates as described previously (Reiser et al., 2004).

\section{Generation of mutants}

Molecular characterization of the pht4;6 T-DNA insertion line was performed using genomic DNA isolated from 4-week-old leaves using primers At5g44370_11, At5g44370_12 and LB-3 (Table S1). cDNA was isolated as described below and amplified using primers At5g44370_29 and At5g44370_30. For complementation of the pht4;6T-DNA line with the endogenous AtPHT4;6 gene (At5g44370), the coding sequence including the native promoter and the $3^{\prime}$ UTR was amplified from genomic DNA using primers At5g44370_23 and At5g44370_24. The sequence was cloned in an EcoRV-linearized pGreen0029 vector (Hellens et al., 2000), and transformed together with the pSoup vector (Hellens et al., 2000) into Agrobacterium tumefaciens. For complementation of the pht4;6 T-DNA mutant with the rice homolog, the entire Os11g08370 coding sequence was amplified using primers Os11.moo753_1 and Os11.moo753_2. The sequence was ligated into a $\mathrm{Kpnl} / \mathrm{Xhol}-\mathrm{cut}$ pET42a(+) expression vector (Merck, www.merckmillipore.com), amplified using primer Os11.moo753_3 and the T7 promotor primer, digested and ligated into Xhol/BamHI-cut pHannibal (Gleave, 1992). The construct was cut using Notl/Spel, cloned into the plant transformation vector pART27 (Gleave, 1992), and used for A. tumefaciens-mediated transformation of Arabidopsis (Clough and Bent, 1998).

\section{Pathogen strains and plant treatments}

Pseudomonas syringae pv. tomato (Pst) DC3000 and Pst DC3000 AvrRpt2 (Whalen et al., 1991; Kunkel et al., 1993) were propagated in $\mathrm{KB}$ medium produced with protease peptone, no. $3(20 \mathrm{~g})$, glycerol $(12 \mathrm{~g}), \mathrm{K}_{2} \mathrm{SO}_{4}(1.5 \mathrm{~g}), \mathrm{MgSO}_{4} * 7 \mathrm{H}_{2} \mathrm{O}(1.5 \mathrm{~g})$ and deionized distilled water $(1 \mathrm{I})$ at $28^{\circ} \mathrm{C}$. Cells were centrifuged for $10 \mathrm{~min}$ at $2500 \mathrm{~g}$, and the pellet was resuspended in $10 \mathrm{~mm} \mathrm{MgCl}_{2}$ to an $\mathrm{OD}_{600}$ of 0.1. Four-week-old plants were infected by infiltration of Pst DC3000 or PstDC3000 AvrRpt2 (5 $\left.\times 10^{5} \mathrm{cfu} \mathrm{ml}^{-1}\right)$ using a needleless syringe. For Northern blot analysis, infected leaves were harvested after several time points post-inoculation, and total RNA was isolated as described below. For quantification of $P$. syringae growth, discs (0.3 cm diameter) of infected leaves were prepared after 0, 1, 2 and 3 days post-inoculation (dpi), and homogenized in $0.5 \mathrm{ml}$ $10 \mathrm{mM} \mathrm{MgCl}_{2}$ solution. Cells were counted after incubation for 2 days at $28^{\circ} \mathrm{C}$ on $\mathrm{KB}$ agar plates supplemented with antibiotics (Rifampicin, Kanamycin).

\section{Gene expression analysis}

The relative accumulation of mRNA was determined by Northern blot analysis as described previously (Jung et al., 2011). Quantitative RT-PCR was performed as described previously (Leroch et al., 2005). The gene-specific primers used are listed in Table S1. Polyubiquitin ubq10 mRNA was used for quantitative normalization.

\section{Subcellular localization}

Established plasmids were used encoding marker proteins for cisGolgi localization (Man1-mRFP, Nebenführ et al., 2002) and transGolgi localization (ST-DsRed, Saint-Jore et al., 2002). Arabidopsis thaliana protoplasts were generated from a cell suspension culture 3 days after sub-cultivation. Subsequently, cells were transformed via PEG-mediated transformation as described previously (Negrutiu 
et al., 1987). Then the protoplasts were incubated in the dark at $26^{\circ} \mathrm{C}$ for a minimum of 20 hs. For CLSM imaging, a Leica TCS SP5 II confocal laser scanning microscope (http://www.leica-microsys tems.com) was used. All images were taken using a Leica HCX PL APO $63 \times / 1.20 \mathrm{w}$ motCORR CS objective. The lasers used were VISArgon for GFP constructs ( $488 \mathrm{~nm} / 496-518 \mathrm{~nm}$ ) and VIS-DPSS 561 for mRFP and DsRed constructs (561 nm/593-636 nm). Post-processing of the images was performed using Leica Application Suite Advanced Fluorescence Lite software. Pinholes were set to 1 Airy unit for each wavelength.

\section{$\mathrm{N}$-glycan analysis by immunoblotting and lectin blots}

Immunoblotting using anti-peroxidase antibody (Sigma) was performed as described previously (Schoberer et al., 2009) using plant tissue harvested from 5 -week-old plants. Total soluble protein $\left(15 \mu \mathrm{g} \mathrm{ml}^{-1}\right)$ was separated SDS-PAGE and transferred to a nitrocellulose membrane. For immunodetection of $\mathrm{N}$-glycans, alkaline phosphatase buffer medium ( $100 \mathrm{~mm}$ Tris/ $\mathrm{HCl}, 100 \mathrm{~mm} \mathrm{NaCl}, 5 \mathrm{~mm}$ $\mathrm{MgCl}_{2}, \mathrm{pH}$ 9.5) supplemented with $220 \mu \mathrm{l}$ 5-Bromo-4-chloro-3 indolyl phosphate (BCIP) (50 mg ml${ }^{-1}$ in $70 \% \mathrm{v} / \mathrm{v}$ dimethylformamide) and $165 \mu \mathrm{l}$ Nitroblue tetrazolium chloride (NBT) $\left(50 \mathrm{mg} \mathrm{ml}^{-1}\right.$ in $50 \%$ $\mathrm{v} / \mathrm{v}$ dimethylformamide) was used. Mannose-containing N-glycans were detected using peroxidase-conjugated Concanvalin A (Sigma) according to the manufacturer's instructions.

\section{NMR}

The ${ }^{31}$ P-NMR spectra were recorded on a standard broad-band $10 \mathrm{~mm}$ probe on a Bruker AMX 600 spectrometer (Bruker, http:// www.bruker.com) with TopSpin software version 1.3. The ${ }^{31} \mathrm{P}-\mathrm{NMR}$ spectra were recorded at $242.9 \mathrm{MHz}$ without lock, using Waltz-based broad-band proton decoupling and a spectral window of $16 \mathrm{kHz}$. Chemical shifts were measured relative to the signal from a glass capillary containing $33 \mathrm{~mm}$ methylene diphosphonate, which is at $18.5 \mathrm{ppm}$ relative to the signal from $85 \% \mathrm{H}_{3} \mathrm{PO}_{4}$. Resonance assignment was performed as described previously (Roberts et al., 1980; Kime et al., 1982).

In vivo ${ }^{31} \mathrm{P}-\mathrm{NMR}$ experiments were performed by packing the leaves into a $10 \mathrm{~mm}$ diameter NMR tube equipped with a perfusion system connected to a peristaltic pump through which aerated thermo-regulated $\left(25^{\circ} \mathrm{C}\right)$ medium $(1 \mathrm{~mm}$ methylene diphosphonate, $1 \mathrm{~mm}$ Mes/Bis-Tris propane (BTP), pH 6.1, $0.4 \mathrm{~mm} \mathrm{CaSO}_{4}$ ) flowed at $10 \mathrm{ml} \mathrm{min}{ }^{-1}$. The quantitative in vivo analyses were performed using a $90^{\circ}$ pulse angle and 6 sec recycle time to give fully relaxed resonance. Phosphate concentration in the vacuole was determined as described by Spickett et al. (1992) by comparing the resonance intensity with that of a glass capillary containing $33 \mathrm{~mm}$ methylene diphosphonate and previously calibrated against standard solutions. The areas of the ${ }^{31} \mathrm{P}$ vacuolar peaks were measured by Lorentzial line-shape analysis, and the values obtained were expressed as a percentage of the volume of tissue in the NMR tube (Spickett et al., 1992).

\section{Histochemical analysis}

For histochemical analysis, leaves of 4-week-old plants were used. Detection of callose was performed as described by Eschrich and Currier (1964). Accumulation of $\mathrm{H}_{2} \mathrm{O}_{2}$ was detected by 3,3'-diaminobenzidine (DAB) staining (Kariola et al., 2005). Trypan blue staining was performed according to a standard method (Cao et al., 1998).

\section{Cell-wall sugar isolation}

Plant cell-wall carbohydrates were isolated as described previously (Foster et al., 2010) with the following modifications. For homo- genization of plant material, a Retsch ball mill (MM301; http:// www.retsch.de) and $40 \mathrm{mg}$ material were used. Starch digestion was performed using 6.7 units $\alpha$-amylase from porcine pancreas (Sigma) and 11 units amyloglucosidase from Aspergillus niger (Sigma).For carbohydrate determination, $10 \mathrm{mg}$ of isolated plant cell wall were used. As an internal standard, $250 \mu \mathrm{l}$ acetone and $50 \mu \mathrm{l}$ inositol solution $\left(5 \mathrm{mg} \mathrm{ml}^{-1}\right.$ ) were added and evaporated under gentle airflow. Weak acid hydrolysis was performed by adding $250 \mu$ of $2 \mathrm{M}$ trifluoroacetic acid to each sample and incubation for $90 \mathrm{~min}$ at $121^{\circ} \mathrm{C}$. Tubes were cooled on ice and centrifuged at $11000 \mathrm{~g}$ for $10 \mathrm{~min}$. Then $150 \mu \mathrm{l}$ supernatant was transferred to new reaction tubes and evaporated. Pellets were resuspended in $300 \mu \mathrm{l}$ 2-propanol, mixed and evaporated at $30^{\circ} \mathrm{C}$ three times. Water $(150 \mu l)$ was added and samples were used for sugar determination as described below.

\section{Metabolite measurement}

Sugar quantification was performed by ion chromatography on a HPLC-RCX-30 $7 \mu \mathrm{m} 4.6 \times 250 \mathrm{~mm}$ column (Hamilton, http://www. hamiltoncomp.com) using an $871 \mathrm{IC}$ compact device (Metrohm, http://www.metrohm.com) followed by amperometric quantification. $\mathrm{NaOH}(0.15 \mathrm{~m})$ was used as the mobile phase with a flow rate of $0.3 \mathrm{ml} \mathrm{min}{ }^{-1}$. The pressure was set to $9.5 \mathrm{MPa}$ at a temperature of $27^{\circ} \mathrm{C}$.

For isolation of anions, plant material was ground under liquid $\mathrm{N}_{2}$, and $1 \mathrm{ml}$ water was added to $100 \mathrm{mg}$, mixed thoroughly and heated for $15 \mathrm{~min}$ at $95^{\circ} \mathrm{C}$. After centrifugation for $15 \mathrm{~min}(18000 \mathrm{~g})$, the supernatant was used for quantification using a 761 IC compact device (Metrohm) on a Metrosep A Supp 4-250/4.0 column (Metrohm), followed by conductometry at a flow rate of $1 \mathrm{ml} \mathrm{min}^{-1}$ and pressure of $8 \mathrm{MPa}$, using $4 \mathrm{~mm} \mathrm{NaHCO}$ and $1 \mathrm{mM} \mathrm{Na}_{2} \mathrm{CO}_{3}$ as the mobile phase. $\mathrm{H}_{2} \mathrm{SO}_{4}(50 \mathrm{~mm})$ was used as a suppressor.

Extraction of SA was performed as described by Meuwly and Metraux (1993). SA was analyzed using a Dionex HPLC system (http://www.dionex.com) with a P680 HPLC pump, an RF 2000 fluorescence detector and a $\mathrm{UCl} 50$ interface (Dionex), equipped with a Nucleodur column $100-5 \mathrm{C}_{18} \mathrm{ec} 250 / 4$ (Machery and Nagel, http://www.mn-net.com). Samples were separated using a flow rate

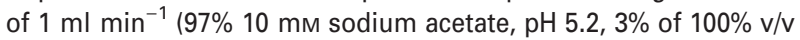
methanol). Fluorescence of SA was detected with an excitation wavelength of $300 \mathrm{~nm}$ and an emission wavelength of $400 \mathrm{~nm}$. Quantification was performed using Chromeleon 6.7 software (Dionex).

\section{ACKNOWLEDGEMENTS}

Work in the laboratories of H.E.N. and K.S. was financially supported by the Deutsche Forschungsgemeinschaft (FOR 1061). Work in the H.E.N. laboratory was further supported by a Reinhard Koselleck grant from the Deutsche Forschungsgemeinschaft and by the Landesschwerpunkt 'Membrantransport'.

\section{SUPPORTING INFORMATION}

Additional Supporting Information may be found in the online version of this article:

Figure S1. Characterization of homozygous T-DNA insertion lines. Figure S2. Complementation of the pht4;6 mutation using the Oryza sativa homolog Os11g08370.

Figure S3. Complementation of the pht4;6 mutation using Arabidopsis thaliana At5g44370.

Figure S4. The PHT4;6 protein is located in the trans-Golgi.

Table S1. Primer used for identification of pht4;6 T-DNA insertion lines, com-plementation of pht4;6 with the rice homologue Os11g08370 and for qRT-PCR studies. 
Please note: As a service to our authors and readers, this journal provides supporting information supplied by the authors. Such materials are peer-reviewed and may be re-organized for online delivery, but are not copy-edited or typeset. Technical support issues arising from supporting information (other than missing files) should be addressed to the authors.

\section{REFERENCES}

Arpat, A.B., Magliano, P., Wege, S., Rouached, H., Stefanovic, A. and Poirier, Y. (2012) Functional expression of PHO1 to the Golgi and transGolgi network and its role in export of inorganic phosphate. Plant J. 71, 479-491.

Bassil, E., Ohto, M., Esumi, T., Tajima, H., Zhu, Z., Cagnac, O., Belmonte, M., Peleg, Z., Yamaguchi, T. and Blumwald, E. (2011) The Arabidopsis intracellular $\mathrm{Na}^{+} / \mathrm{H}^{+}$antiporters $\mathrm{NHX5}$ and $\mathrm{NHX6}$ are endosome-associated and necessary for plant growth and development. Plant Cell, 23, 224-239.

Bucher, M. (2007) Functional biology of plant phosphate uptake at root and mycorrhiza interfaces. New Phytol. 173, 11-26.

Cao, H., Li, X. and Dong, X. (1998) Generation of broad-spectrum disease resistance by overexpression of an essential regulatory gene in systemic acquired resistance. Proc. Natl Acad. Sci. USA, 95, 6531-6536.

Chang, A.B., Lin, R., Keith, S.W., Tran, C.V. and Saier, M.H. Jr (2004) Phylogeny as a guide to structure and function of membrane transport proteins. Mol. Membr. Biol. 21, 171-181.

Clough, S.J. and Bent, A.F. (1998) Floral dip: a simplified method for Agrobacterium-mediated transformation of Arabidopsis thaliana. Plant J. 16 735-743.

Collins, N.C., Thordal-Christensen, H., Lipka, V. et al. (2003) SNARE-protein-mediated disease resistance at the plant cell wall. Nature, 425,973 977.

Cubero, B., Nakagawa, Y., Jiang, X.Y., Miura, K.J., Li, F., Raghothama, K.G., Bressan, R.A., Hasegawa, P.M. and Pardo, J.M. (2009) The phosphate transporter PHT4;6 is a determinant of salt tolerance that is localized to the Golgi apparatus of Arabidopsis. Mol. Plant, 2, 535-552.

Denecke, J., Carlsson, L.E., Vidal, S., Hoglund, A.S., Ek, B., van Zeijl, M.J., Sinjorgo, K.M. and Palva, E.T. (1995) The tobacco homolog of mammalian calreticulin is present in protein complexes in vivo. Plant Cell, 7, 391-406.

Eschrich, W. and Currier, H.-B. (1964) Identification of callose by its diachrome and fluorochrome reactions. Stain Technology, 39, 303-307.

Espen, L., Dell'Orto, M., De Nisi, P. and Zocchi, G. (2000) Metabolic responses in cucumber (Cucumis sativus L.) roots under Fe-deficiency: a ${ }^{31} \mathrm{P}$-nuclear magnetic resonance in vivo study. Planta, 210, 985-992.

Fischer, K., Kammerer, B., Gutensohn, M., Arbinger, B., Weber, A., Häusler, R. and Flügge, U.I. (1997) A new class of plastidic phosphate translocator: a putative link between primary and secondary metabolism by the phosphoenolpyruvate/phosphate antiporter. Plant Cell, 9, 453-462.

Foster, C.E., Martin, T.M. and Pauly, M. (2010) Comprehensive compositional analysis of plant cell walls (lignocellulosic biomass) part II: carbohydrates. J. Vis. Exp. 12, 1837

Frank, J., Kaulfürst-Soboll, H., Rips, S., Koiwa, H. and von Schaewen, A. (2008) Comparative analyses of Arabidopsis complex glycan 1 mutants and genetic interaction with staurosporin and temperature sensitive3a. Plant Physiol. 148, 1354-1367.

Gleave, A.P. (1992) A versatile binary vector system with a T-DNA organisational structure conducive to efficient integration of cloned DNA into the plant genome. Plant Mol. Biol., 20, 1203-1207.

Guo, B., Irigoyen, S., Fowler, T.B. and Versaw, W.K. (2008a) Differential expression and phylogenetic analysis suggest specialization of plastidlocalized members of the PHT4 phosphate transporter family for photosynthetic and heterotrophic tissues. Plant Signal. Behav. 3, 784-790.

Guo, B., Jin, Y., Wussler, C., Blancaflor, E.B., Motes, C.M. and Versaw, W.K. (2008b) Functional analysis of the Arabidopsis PHT4 family of intracellular phosphate transporters. New Phytol. 177, 889-898.

Handford, M.G., Sicilia, F., Brandizzi, F., Chung, J.H. and Dupree, P. (2004) Arabidopsis thaliana expresses multiple Golgi-localised nucleotide-sugar transporters related to GONST1. Mol. Genet. Genomics, 272, 397-410.

Hellens, R.P., Edwards, E.A., Leyland, N.R., Bean, S. and Mullineaux, P.M (2000) pGreen: a versatile and flexible binary Ti vector for Agrobacteriummediated plant transformation. Plant Mol. Biol. 42, 819-832.
Hering, K.W., Karaveg, K., Moremen, K.W. and Pearson, W.H. (2005) A practical synthesis of kifunensine analogues as inhibitors of endoplasmic reticulum $\alpha$-mannosidase I. J. Org. Chem. 70, 9892-9904.

Hirschberg, C.B. (1997) Transporters of nucleotide sugars, nucleotide sulfate and ATP in the Golgi apparatus membrane: where next? Glycobiology, 7, 169-171.

Jung, B., Hoffmann, C. and Möhlmann, T. (2011) Arabidopsis nucleoside hydrolases involved in intracellular and extracellular degradation of purines. Plant J. 65, 703-711.

Kammerer, B., Fischer, K., Hilpert, B., Schubert, S., Gutensohn, M., Weber, A and Flügge, U.I. (1998) Molecular characterisation of a carbon transporter in plastids from heterotrophic tissues: the glucose 6-phosphate/phosphate antiporter. Plant Cell, 10, 105-117.

Kang, J.S., Frank, J., Kang, C.H. et al. (2008) Salt tolerance of Arabidopsis thaliana requires maturation of $\mathrm{N}$-glycosylated proteins in the Golgi apparatus. Proc. Natl Acad. Sci. USA, 105, 5933-5938.

Kariola, T., Brader, G., Li, J. and Palva, E.T. (2005) Chlorophyllase 1, a damage control enzyme, affects the balance between defense pathways in plants. Plant Cell, 17, 282-294.

Kime, M.J., Ratcliffe, R.G. and Loughman, B.C. (1982) The application of ${ }^{31} \mathrm{P}$ nuclear magnetic resonance to higher plant tissue. J. Exp. Bot. 33, 670-681.

Koiwa, H., Li, F., McCully, M.G. et al. (2003) The STT3a subunit isoform of the Arabidopsis oligosaccharyltransferase controls adaptive responses to salt/ osmotic stress. Plant Cell, 15, 2273-2284.

Krebs, M., Beyhl, D., Gorlich, E., Al-Rasheid, K.A., Marten, I., Stierhof, Y.D. Hedrich, R. and Schumacher, K. (2010) Arabidopsis V-ATPase activity at the tonoplast is required for efficient nutrient storage but not for sodium accumulation. Proc. Natl Acad. Sci. USA, 107, 3251-3256.

Kunkel, B.N., Bent, A.F., Dahlbeck, D., Innes, R.W. and Staskawicz, B.J. (1993) RPS2, an Arabidopsis disease resistance locus specifying recognition of Pseudomonas syringae strains expressing the avirulence gene avrRpt2. Plant Cell, 5, 865-875.

Kwon, C., Neu, C., Pajonk, S. et al. (2008) Co-option of a default secretory pathway for plant immune responses. Nature, 451, 835-840.

Lai, E., Teodoro, T. and Volchuk, A. (2007) Endoplasmic reticulum stress: signaling the unfolded protein response. Physiology, 22, 193-201.

Leroch, M., Kirchberger, S., Haferkamp, I., Wahl, M., Neuhaus, H.E. and Tjaden, J. (2005) Identification and characterization of a novel plastidic adenine nucleotide uniporter from Solanum tuberosum. J. Biol. Chem. 280 17992-18000.

Liu, J.X. and Howell, S.H. (2010) Endoplasmic reticulum protein quality control and its relationship to environmental stress responses in plants. Plant Cell, 22, 2930-2942.

Maeda, Y. and Kinoshita, T. (2010) The acidic environment of the Golgi is critical for glycosylation and transport. Methods Enzymol. 480, 495-510.

Mandal, D.K. and Brewer, C.F. (1993) Differences in the binding affinities of dimeric concanavalin A (including acetyl and succinyl derivatives) and tetrameric concanavalin A with large oligomannose-type glycopeptides. Biochemistry, 32, 5116-5120.

Martinoia, E., Maeshima, M. and Neuhaus, H.E. (2007) Vacuolar transporters and their essential role in plant metabolism. J. Exp. Bot. 58, 83-102.

Mazel, A., Leshem, Y., Tiwari, B.S. and Levine, A. (2004) Induction of salt and osmotic stress tolerance by overexpression of an intracellular vesicle trafficking protein AtRab7 (AtRabG3e). Plant Physiol. 134, 118-128.

Meuwly, P. and Metraux, J.P. (1993) Ortho-anisic acid as internal standard for the simultaneous quantitation of salicylic acid and its putative biosynthetic precursors in cucumber leaves. Anal. Biochem. 214, 500-505.

Miyaji, T., Echigo, N., Hiasa, M., Senoh, S., Omote, H. and Moriyama, Y. (2008) Identification of a vesicular aspartate transporter. Proc. Natl Acad. Sci. USA, 105, 11720-11724.

Morita-Yamamuro, C., Tsutsui, T., Sato, M. et al. (2005) The Arabidopsis gene $C A D 1$ controls programmed cell death in the plant immune system and encodes a protein containing a MACPF domain. Plant Cell Physiol. 46, 902-912.

Müller, R., Morant, M., Jarmer, H., Nilsson, L. and Nielsen, T.H. (2007) Genome-wide analysis of the Arabidopsis leaf transcriptome reveals interaction of phosphate and sugar metabolism. Plant Physiol. 143, 156-171.

Nakamura, Y., Koizumi, R., Shui, G., Shimojima, M., Wenk, M.R., Ito, T. and Ohta, H. (2009) Arabidopsis lipins mediate eukaryotic pathway of lipid metabolism and cope critically with phosphate starvation. Proc. Natl Acad. Sci. USA, 106, 20978-20983. 
Nebenführ, A., Ritzenthaler, C. and Robinson, D.G. (2002) Brefeldin A: deciphering an enigmatic inhibitor of secretion. Plant Physiol. 130, 1102-1108.

Negrutiu, I., Shillito, R., Potrykus, I., Biasini, G. and Sala, F. (1987) Hybrid genes in the analysis of transformation conditions. Plant Mol. Biol. 8, 363-373.

Peiter, E., Montanini, B., Gobert, A., Pedas, P., Husted, S., Maathuis, F.J., Blaudez, D., Chalot, M. and Sanders, D. (2007) A secretory pathway-localized cation diffusion facilitator confers plant manganese tolerance. Proc. Natl Acad. Sci. USA, 104, 8532-8537.

Petersen, M., Brodersen, P., Naested, H. et al. (2000) Arabidopsis MAP kinase 4 negatively regulates systemic acquired resistance. Cell, 103, 1111-1120.

Pratt, J., Boisson, A.M., Gout, E., Bligny, R., Douce, R. and Aubert, S. (2009) Phosphate (Pi) starvation effect on the cytosolic Pi concentration and $\mathrm{Pi}$ exchanges across the tonoplast in plant cells: an in vivo ${ }^{31} \mathrm{P}$-nuclear magnetic resonance study using methylphosphonate as a $\mathrm{Pi}$ analog. Plant Physiol. 151, 1646-1657.

Rausch, C. and Bucher, M. (2002) Molecular mechanisms of phosphate transport in plants. Planta, 216, 23-37.

Reimer, R.J. and Edwards, R.H. (2004) Organic anion transport is the primary function of the SLC17/type I phosphate transporter family. Pflügers Arch. 447, 629-635.

Reiser, J., Linka, N., Lemke, L., Jeblick, W. and Neuhaus, H.E. (2004) Molecular physiological analysis of the two plastidic ATP/ADP transporters from Arabidopsis thaliana. Plant Physiol. 136, 3524-3536.

Roberts, J.K.M., Ray, P.M., Wade-Jardetzky, N. and Jardetzky, O. (1980) Estimation of cytoplasmic and vacuolar $\mathrm{pH}$ in higher plant cells by ${ }^{31} \mathrm{P}$ NMR. Nature, 283, 870-872.

Roth, C., Menzel, G., Petétot, J.M., Rochat-Hacker, S. and Poirier, Y. (2004) Characterization of a protein of the plastid inner envelope having homology to animal inorganic phosphate, chloride and organic-anion transporters. Planta, 218, 406-416.

Saint-Jore, C.M., Evins, J., Batoko, H., Brandizzi, F., Moore, I. and Hawes, C. (2002) Redistribution of membrane proteins between the Golgi apparatus and endoplasmic reticulum in plants is reversible and not dependent on cytoskeletal networks. Plant J. 29, 661-678.

Sawada, K., Echigo, N., Juge, N., Miyaji, T., Otsuka, M., Omote, H., Yamamoto, A. and Moriyama, Y. (2008) Identification of a vesicular nucleotide transporter. Proc. Natl Acad. Sci. USA, 105, 5683-5686.

Schoberer, J., Vavra, U., Stadlmann, J., Hawes, C., Mach, L., Steinkellner, H. and Strasser, R. (2009) Arginine/lysine residues in the cytoplasmic tail promote ER export of plant glycosylation enzymes. Traffic, 10, 101-115.

Shah, J. (2003) The salicylic acid loop in plant defense. Curr. Opin. Plant Biol. 6, 365-371.

Shi, H., Kim, Y., Guo, Y., Stevenson, B. and Zhu, J.K. (2003) The Arabidopsis SOS5 locus encodes a putative cell surface adhesion protein and is required for normal cell expansion. Plant Cell, 15, 19-32.
Shin, H., Shin, H.S., Dewbre, G.R. and Harrison, M.J. (2004) Phosphate transport in Arabidopsis: Pht1;1 and Pht1;4 play a major role in phosphate acquisition from both low- and high-phosphate environments. Plant J. 39, 629-642.

Spickett, C.M., Smirnoff, N. and Ratcliffe, R.G. (1992) Metabolic response of maize roots to hyperosmotic shock: an in vivo ${ }^{31} \mathrm{P}$ nuclear magnetic resonance study. Plant Physiol. 99, 856-863.

Stefanovic, A., Arpat, A.B., Bligny, R., Gout, E., Vidoudez, C., Bensimon, M. and Poirier, Y. (2011) Over-expression of PHO1 in Arabidopsis leaves reveals its role in mediating phosphate efflux. Plant J. 66, 689-699.

Thulke, O.U. and Conrath, U. (1998) Salicylic acid has a dual role in the activation of defense related genes in parsley. Plant J. 14, 35-42.

Ticconi, C.A., Lucero, R.D., Sakhonwasee, S., Adamson, A.W., Creff, A. Nussaume, L., Desnos, T. and Abel, S. (2009) ER-resident proteins PDR2 and LPR1 mediate the developmental response of root meristems to phosphate availability. Proc. Natl Acad. Sci. USA, 106, 14174-14179.

Uemura, T., Kim, H., Saito, C., Ebine, K., Ueda, T., Schulze-Lefert, P. and Nakano, A. (2012) Qa-SNAREs localized to the trans-Golgi network regulate multiple transport pathways and extracellular disease resistance in plants. Proc. Natl Acad. Sci. USA, 109, 1784-1789.

Uknes, S., Mauch-Mani, B., Moyer, M., Potter, S., Williams, S., Dincher, S., Chandler, D., Slusarenko, A., Ward, E. and Ryals, J. (1992) Acquired resistance in Arabidopsis. Plant Cell, 4, 645-656.

Wang, Y., Ribot, C., Rezzonico, E. and Poirier, Y. (2004) Structure and expression profile of the Arabidopsis $\mathrm{PHO} 1$ gene family indicates a broad role in inorganic phosphate homeostasis. Plant Physiol. 135, $400-$ 411.

Wang, H.X., Weerasinghe, R.R., Perdue, T.D., Cakmakci, N.G., Taylor, J.P., Marzluff, W.F. and Jones, A.M. (2006) A Golgi-localized hexose transporter is involved in heterotrimeric $G$ protein-mediated early development in Arabidopsis. Mol. Biol. Cell, 17, 4257-4269.

Weber, A.P., Schwacke, R. and Flügge, U.I. (2005) Solute transporters of the plastid envelope membrane. Annu. Rev. Plant Biol. 56, 133-164.

Whalen, M.C., Innes, R.W., Bent, A.F. and Staskawicz, B.J. (1991) Identification of Pseudomonas syringae pathogens of Arabidopsis and a bacterial locus determining avirulence on both Arabidopsis and soybean. Plant Cell, 3, 49-59.

Wick, P., Gansel, X., Oulevey, C., Page, V., Studer, I., Dürst, M. and Sticher, L. (2003) The expression of the t-SNARE AtSNAP33 is induced by pathogens and mechanical stimulation. Plant Physiol. 132, 343-351.

Wilson, I.B.H., Harthill, J.E., Mullin, N.P., Ashford, D.A. and Altmann, F. (1998) Core $\beta-1,3$-fucose is a key part of the epitope recognized by antibodies reacting against plant $\mathrm{N}$-linked oligosaccharides and is present in a wide variety of plant extracts. Glycobiology, 8, 651-661.

Zimmermann, P., Hirsch-Hoffmann, M., Hennig, L. and Gruissem, W. (2004) GENEVESTIGATOR. Arabidopsis microarray database and analysis tool box. Plant Physiol. 136, 2621-2632. 